\title{
RESOLUTION EXPERIMENTS FOR NW PACIFIC SUBDUCTION ZONE TOMOGRAPHY
}

\author{
Wim Spakman ${ }^{1}$, Seth Stein ${ }^{2}$, Rob van der Hilst ${ }^{1}$ and Rinus Wortel ${ }^{1}$
}

Abstract. We investigate the resolving power of ISC/NEIC P travel time data in tomographic inversions for the geometry of the subduction zones in the NW Pacific. From thermal models for the Kurile, Japan, Izu-Bonin, Mariana and Ryukyu slabs, we generate three dimensional synthetic velocity anomalies for subducting slabs which are then projected onto a cell model for the uppermost $1400 \mathrm{~km}$ of the mantle. Using these synthetic models we compute synthetic delay times for ray paths corresponding to the source and receiver locations used for the actual data, add Gaussian noise, invert the synthetic data, and compare the resulting velocity structure to the initial synthetic models. This comparison is illustrated for sections through the Kuriles and the Mariana arcs. A variety of resolution artifacts are observed, which in many cases resemble features visible in the tomographic results obtained from inverting the actual ISC/NEIC data.

\section{Introduction}

The development of techniques for the determination of three dimensional earth structure from inversion of seismic travel times [Aki et al., 1977] has provided a powerful tool for tectonic studies [Nolet, 1987, Thurber and Aki, 1987]. Body wave tomography has been used to illustrate the nature of mantle heterogencity [Dziewonski, 1984; Grand, 1987]. It is especially successful in delineating steeply dipping anomalous velocity regions such as subducting slabs [Hirahara, 1981; Kamiya et al. 1988; Spakman et al., 1988; Van der Hilst, 1989; Zhou, 1988; Zhou and Clayton, preprint, 1988], due to the thermal contrast between the cold downgoing slab and warmer ambient mantle, long exploited in travel time studies [Toksoz et al., 1971; Slecp, 1973; Engdahl et al., 1977; Jordan, 1977; Creager and Jordan, 1984; 1986] and recently incorporated in waveform studies [Silver and Chan, 1986 Vidale, 1987; Cormier, 1989].

Since in most cases [Humphreys et al. [1984] being a striking exception) the subducting slab had been previously identified from the Wadati-Benioff Zone seismicity, an interesting aspect of travel time data is their potential resolving power for the geometry of the slab. In particular, the travel time data are often interpreted as showing a high velocity region extending beyond the deepest seismicity, sometimes extending to depths below the $670 \mathrm{~km}$ discontinuity. In other cases, the slab appears to bottom at this depth, suggesting an inability to penetrate this discontinuity. These data are thus crucial to the question of whether downgoing slabs can penetrate the discontinuity, and hence to the question of the existence and evolution of a stratified mantle [Jordan, 1977; Richter, 1979; Davies, 1984; Silver et al., 1988].

Here we explore how well body wave tomography can resolve the structure of downgoing slabs in the NW Pacific. Starting from thermal modeling of slab subduction we derive a three dimensional synthetic velocity model of slabs, and investigate how well this slab geometry can be recovered in a tomographic experiment using most of the currently available $\mathrm{P}$ wave travel time data pertinent to the NW Pacific mantle.

${ }_{2}^{1}$ Department of Theoretical Geophysics, University of Utrecht. $2^{2}$ Department of Geological Sciences, Northwestern University.

Copyright 1989 by the American Geophysical Union.

Paper number 89GL01677.

0094-8276/89/89GL-01677\$03.00
Thermal models and seismic velocity models for slabs

The region studied (Figure 1) contains five major subducting slabs: Kurile, Japan, Izu-Bonin, Mariana and Ryukyu. We computed the temperature field for each slab using a finite difference numcrical model [Sleep, 1973; Toksoz et al., 1973] incorporating mantle flow, for the appropriate values of slab age, convergence rate, and dip. The temperature effects of adiabatic compression were added to the calculated potential temperatures using values of $1.05 \times 10^{3} \mathrm{Jkg}^{-10} \mathrm{C}^{-1}$ the heat capacity and $3.6 \times 10^{-5 \circ} \mathrm{C}^{-1}$ for the coefficient of thermal expansion. These satisfy the constraint that the olivine to spincl phase change occurs at approximately $400 \mathrm{~km}$ depth and $1500^{\circ} \mathrm{C}$ [Bina and Wood, 1986]. The slab's thermal structure prior to subduction is described by a finite thickness plate [Crough, 1977; Wortel, 1980; see also Wortel and Vlaar 1988] with a temperature at the base of the lithosphere of $1330^{\circ}$.

The temperatures were converted to seismic P-velocity assuming a $\partial \mathrm{v}_{\mathrm{p}} / \partial \mathrm{T}$ value of $-0.5 \mathrm{~m} / \mathrm{sec}-{ }^{\circ} \mathrm{C}$. The two dimensional models for each slab were rotated about a pole for each island arc (Figure 1), giving three dimensional synthetic velocity models. Velocity anomalies are obtained by subtracting the Jeffreys-Bullen (JB) model which is used as a reference model for tomography. The velocity anomalies were then projected onto a cell model for the uppermost $1400 \mathrm{~km}$ of the mantle to obtain the cell anomaly values of the 3-dimensional slab models. The slab models are not intended to describe the full complexity of the subduction process. Though simplified, the thermal models presumably represent the deeper portions of the slab better than an a priori velocity model. Since we are studying primarily the resolution attainable with delay time tomography for the structure of deeper portions of the

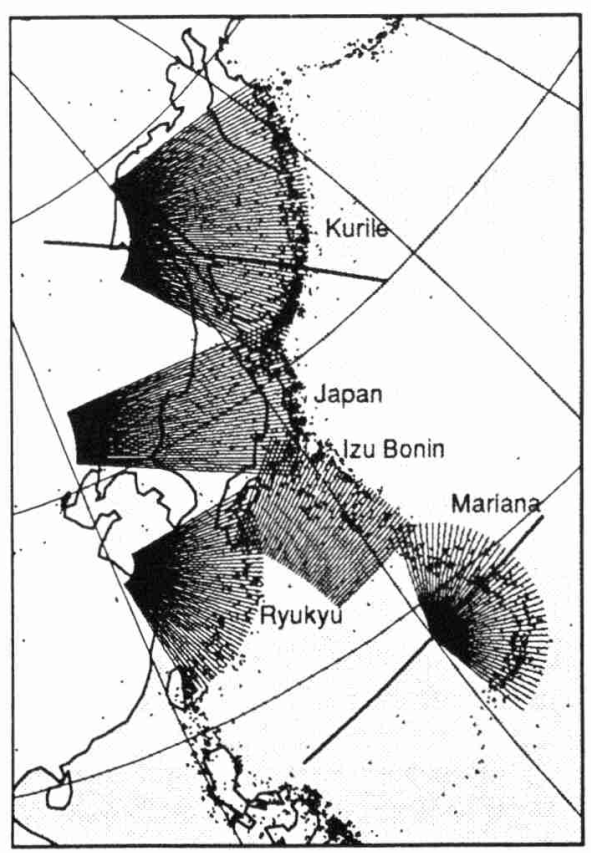

Fig. 1: Map of the NW-Pacific. Light lines indicate two dimensional slices radial to the arc pole along which the two dimensional thermal models are computed. Heavy lines indicate cross sections through the Kuriles and Marianas discussed in the paper. 
slab, features such as a low velocity wedge above the slab are not included.

\section{Delay time tomography}

The linearized tomographic method used [Spakman, 1988; Spakman and Nolet, 1988] is based on a cell division of the mantle below the region shown in Figure 1. The cell model comprises $518321^{\circ} \times 1^{\circ}$ cells arranged in 19 layers. Layer thicknesses vary from $33 \mathrm{~km}$ in the uppermost layers to $70 \mathrm{~km}$ around $670 \mathrm{~km}$, and to $100 \mathrm{~km}$ at a depth of $1400 \mathrm{~km}$. Besides the slowness anomalies in cells the inversion method accounts for the inevitable effects of earthquake mislocation and station statics on the data, which leads to 23059 additional unknowns. To suppress the influence of data errors on the inversion result, the solution is slightly damped and smoothed (filtered) during the inversion [see Spakman and Nolet, 1988].

For the actual data inversions we used $\mathrm{P}$ delay times selected from the ISC and NEIC catalogs for the years 1964-1987. Only events observed in at least 10 stations (up to $90^{\circ}$ ) and located within the region were sclected, and only $\mathrm{P}$ delay times between the limits of -5 and +5 seconds were admitted. Thus we obtained about 1.4 million data. Since these are determined with respect to the JB travel time tables, ray paths are computed from the 1dimensional JB velocity model. Using millions of data it is at present computationally too expensive to perform 3-dimensional ray tracing through laterally heterogeneous velocity structures. For this reason the tomographic scheme is a one step linear approximation of the strongly non-linear tomographic problem [e.g. Nolet, 1987; Spakman, 1988].

Inversions were performed on the actual data and also on synthetic data. Synthetic P delay times were computed from synthetic slab models using the ray paths corresponding to the actual delay time data. After adding synthetic noise we inverted the data and compared the resulting velocity structure to the initial synthetic models. We carried out these experiments for slabs restricted to the upper mantle, and for slabs penetrating into the lower mantle, for a variety of slab geometries and temperature (velocity) models. The examples presented here are for slabs that terminate at $670 \mathrm{~km}$ depth.

In all synthetic inversions we added Gaussian noise with a large standard deviation to the data to mimic actual ISC/NEIC delay times closely $\left(\sigma_{\text {noise }}=1.0 \mathrm{sec}, \quad \mathrm{RMS}_{\text {data }}=0.44 \mathrm{sec}\right.$ $\mathrm{RMS}_{\text {data+noise }}=1.09 \mathrm{sec}$ ). The addition of noise makes the synthetic data inconsistent, which influences the attainable resolution, in particular in regions where the illumination of the model by rays is dominant in certain directions. Synthetic tests which do not use noisy data offer less realistic estimates of accuracy and spatial resolution.

\section{Results}

The essence of the experiment is the comparison of the synthetic model to its tomographic image. The differences between the two result from lack of accuracy and spatial resolution in the tomographic imaging.

Figure 2 shows the results for a cross section through the Kurile arc (Figure 1). Figure 2a illustrates results from the inversion of the actual delay time data. In the upper mantle the irregularly shaped dipping positive anomaly (cross hatched) can be interpreted as the blurred image of the Kurile slab. Below 400 $\mathrm{km}$ the anomaly associated with the slab flattens and splits into two parts; one extending laterally, and one part 'penetrating' the lower mantle, where the anomaly broadens and can be followed to $1400 \mathrm{~km}$ depth. In the NW Pacific similar anomaly patterns have also been obtained by Zhou [1988], Zhou and Clayton [preprint, 1988] and Kamiya et al. [1988] and have been interpreted in terms of slab associated structure.
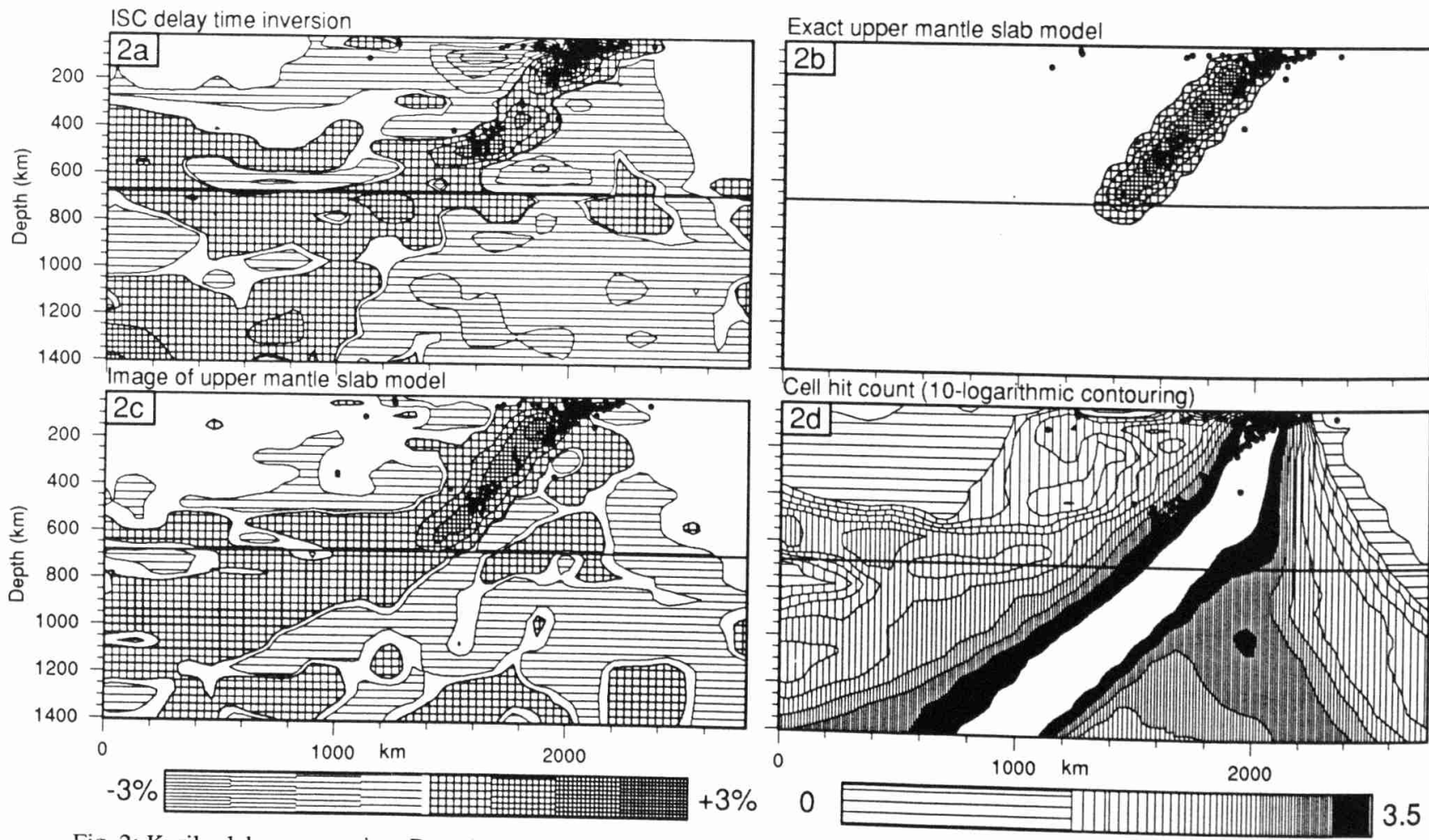

Fig. 2: Kurile slab cross section. Dots denote earthquake epicenters. 2a: result of inverting real delay times. $2 \mathrm{~b}$ : the synthetic corresponding (noisy) synthetic data. $2 \mathrm{~d}$. the thermal modeling and projected onto the cell model. $2 \mathrm{c}$ : result of inverting the refers to velocity anomalies in percentages relative to the ambient in 10 -logarithmic contouring The legend below panel $2 \mathrm{c}$ zero values. The other legend refers to the hit count ambient Jeffreys-Bullen mantle velocity. White areas in $2 \mathrm{a}-\mathrm{c}$ depict exceeding 3.5. Horizontal hatching from 0 to 1.5 , followed by eight intervals of 0.25 . depict either zero values or values 
The question we address here is whether these two features represent an image of real, possibly slab related, structure or whether these are due to lack of accuracy and spatial resolution in the image. Some insight can be obtained from the synthetic tests with 3 -D slab models. Figure $2 b$ shows the exact (input) slab model along the same cross section. The inversion result (response) is shown in Figure 2c. The core of the synthetic slab of Figure $2 b$ is well recovered. All anomalies outside this core such as the two apparent extensions of the slab, one shallowing in the deeper upper mantle and one penetrating the lower mantle must be regarded as resolution artifacts. These artifacts resemble the anomaly patterns discussed for Figure 2a, suggesting that some of the features associated with the slab anomaly in Figure $2 \mathrm{a}$ are more likely to be resolution artifacts than images of real velocity structure.

Two important effects contribute to these artifacts: (i) the combined effects of data errors and ray illumination (sampling) of the cell model, and (ii) the influence of the reference model on the delay time data and ray paths.

The results of inversion of noise-free synthetic data (derived from the 3-D slab model) exhibit the inferred artifacts to a smaller extent. Noisy data lead to inconsistent tomographic equations which, combined with nearly-dependent (parts) of the equations, facilitate the smearing of poorly resolved anomalies along directions of preferential ray illumination (i.e. the nearlydependent parts of the tomographic equations). The ray illumination is illustrated by the cell hit count (the number of rays sampling a cell) in Figure $2 d$. Although the hit count is a scalar measure of the ray sampling of the cells, it is possible to infer preferential directions of ray illumination by following the (relative) maxima in the contour plot. Note that these directions correlate with the resolution artifacts in Figure 2a. The ray illumination is fundamental for understanding a tomographic image, as it not only illustrates the smearing of anomalies, but $i$ also strongly affects the convergence propertics of the cell anomaly solution [Spakman 1988; Spakman and Nolet 1988].

The influence of reference model (e.g. JB model) adopted on the tomographic results is discussed by Van der Hilst and Spakman [1988]. They demonstrate that strong mantle velocity gradients, not present in the reference model, can map into an apparent horizontal layering or streaking in the tomographic image: as positive anomalies below $400 \mathrm{~km}$, negative just above $670 \mathrm{~km}$ and again positive just below $670 \mathrm{~km}$. How large the horizontal extent of this layering is in the image depends on the ray sampling. In Figure $2 a$ this effect is visible between horizontal distances of 400 and $1200 \mathrm{~km}$, where it is superimposed on the effects of along ray path smearing. In the synthetic result (2c) only the anomaly smearing effects are visible, since the synthetic data are computed with respect to the assumed reference model.

Figure 3 shows the corresponding series of panels for a cross section through the Mariana subduction zone. The image resulting from the inversion of synthetic data (Figure 3c) extends to depths well below the synthetic model (Figure $3 b$ ) and the deepest seismicity. Again we find similarities between anomaly patterns in the real data result (Figure 3a) and the synthetic result, and similar explanations to those given for the Kurile cross section apply.

\section{Discussion}

Our experiment examines only the current resolving power of ' delay time tomography for velocity structures in the NW Pacific using most of the data (ray paths) available. It does not dircctly provide additional insight into the subduction process, but the results illustrate the limitation of the use of delay time tomography for imaging this process. Specifically, we have demonstrated that large scale resolution artifacts in the synthetic inversion results resemble anomaly patterns in the real data results.

Synthetic tests for resolution and accuracy estimates can be performed in various ways. In our inversions we tried to mimic the real data case by using synthetic data with a large signal to noise ratio. Morcover, we incorporated extra unknowns in the inversion procedure which account for the effects of velocity heterogeneity on the event mislocation with respect to the ISC (reference) location. Alternatively, the effects of the ray sampling alone can be tested by excluding data errors and event mislocation effects from the synthetic inversions [e.g. Zhou 1988; Zhou and Clayton, preprint 1988]. Such tests, however, mimic the real data case less well and resolution estimates derived are thus less applicable to inversion results obtained with real data [Spakman 1988; Spakman and Nolet 19881.

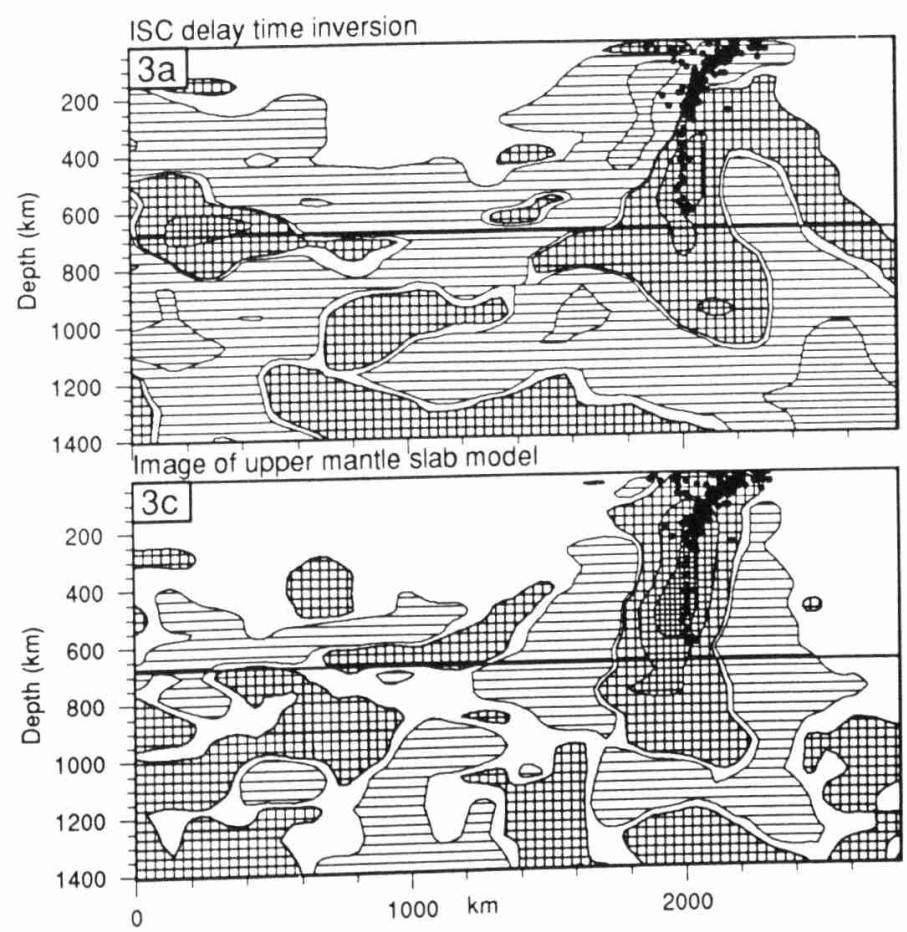

Exact upper mantle slab model
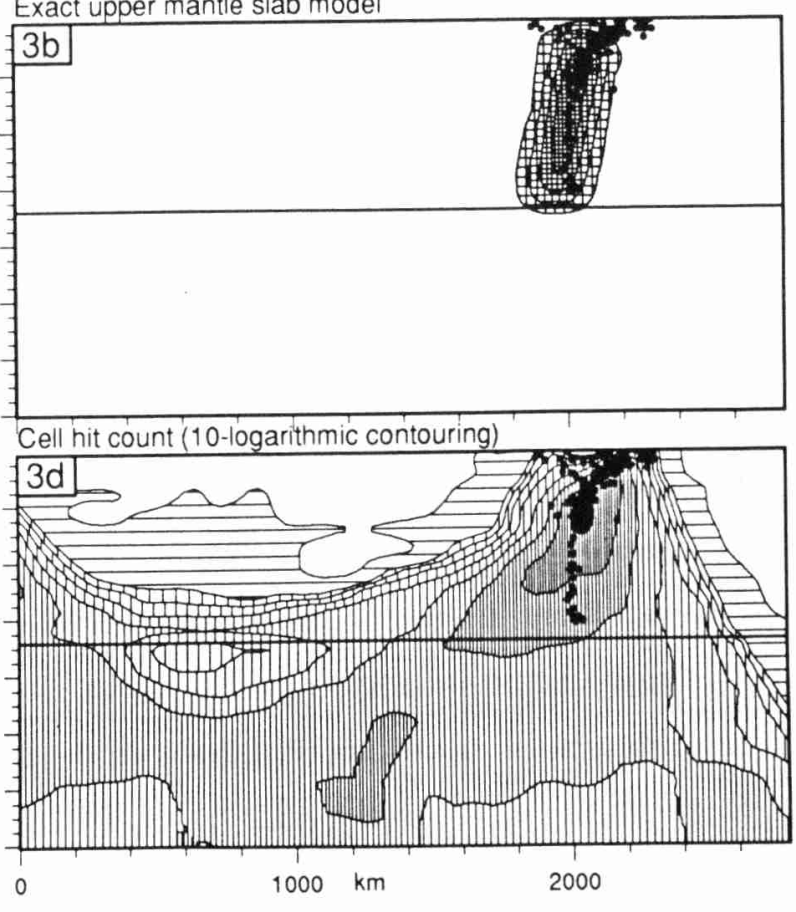

Fig. 3: Mariana slab cross section. Description of the four panels as in the caption of fig. 2. 
We have found that the lower mantle extension of the slab anomalies in the Kurile and Mariana zone (Figures 2a, 3a) may result from lack of spatial resolution. Expcriments with slab models extending to $900 \mathrm{~km}$ of depth show, however, similar artifacts. This makes it difficult to infer from in the real data results whether slabs penetrate into the lower mantle.

It is worth noting that subducting slabs are not as easily identified in the results of inversion of real data. The discrepancies between the real case and the synthetic experiments may result from several effects. The slab models are relatively simple and may differ in important aspects from the real situation. Morcover, the synthetic data do not fully incorporate some complexities of real delay times such as event location, reference model dependences, and specific data error distributions other than Gaussian [Spakman 1988; Van der Hilst and Spakman 1989].

We conclude that synthetic data experiments offer some useful insight into the resolution of subduction zone tomography in the NW Pacific. Features in the results of inversions of real data which resemble features well resolved in the synthetic data experiments thus acquire additional credibility. Conversely, features in the real data inversion results should be treated with caution if they resemble artifacts in the images produced by inversion of the synthetic data.

Acknowledgements. This research was supported by NSF grants EAR 8618038 and INT 8610654 and NASA grant NAG51156. We thank Norman Slecp for his thermal modeling code, Bernard Dost for the use of the ORFEUS computing facilitics, and an anonymous reviewer for useful comments. The Dutch foundation of university computer facilities (SURF) and the Dutch science foundation (NWO) funded the use of the SARA supercomputer. Additional data were collected at the NEIC by RvdH (NATO grant 0910/87).

\section{References}

Aki, K., A. Christofferson, and S. Husebye, Determination of the three dimensional structure of the lithosphere, J. Geophys Res., 82, 277-296, 1977.

Bina, C. R., and B. J. Wood, The $400 \mathrm{~km}$ seismic discontinuity and the proportion of olivine in the Earth's upper mantle, Nature, 324, 449-451, 1986.

Cormier, V., Slab diffraction of S waves, J. Geophys. Res. 94 3006-3024, 1989

Creager, K. C., and T. H. Jordan, Slab penetration into the lower mantle, J. Geophys. Res., 89, 3031-3049, 1984.

Creager, K. C., and T. H. Jordan, Slab penetration into the lower mantle beneath the Mariana and other island arcs of the northwest Pacific, J. Geophys. Res., 91, 3573-3589, 1986.

Crough, S. T., Approximate solutions for the formation of the lithosphere, Phys. Earth Planet. Inter., 14, 365-377, 1977.

Davies, G. F., Lagging mantle convection, the geoid and mantle structure, Earth Planet. Sci. Lett., 69, 187-194, 1984

Dziewonski, A. M., Mapping the lower mantle: determination of lateral heterogeneity in $\mathrm{P}$ velocity up to degree and order 6 , GJR, 89, 5929-5952, 1984 .

Engdahl, E. R., N. H. Sleep, and M. T. Lin, Plate effects in North Pacific subduction zones, Tectonophysics, 37, 95-116, 1977.

Grand, S. P., Tomographic inversion for shear velocity beneath the North American plate, J. Geophys. Res., 92, 14,065-14,090, 1987.

Hirahara, K., Three dimensional seismic structure beneath southwest Japan: the subducting Phillipine Sea plate, Tectonophysics, 79, 1-44, 1981.

Humphreys, E., R. Clayton, and B. Hager, A tomographic image of mantle structure beneath southern California, Geophys. Res. Lett., 11, 625-627, 1984.
Jordan, T. H., Lithospheric slab penetration into the lower mantle bencath the Sea of Okhotsk, J. Geophys., 43, 473-496, 1977.

Kamiya, S., Miyatake, T., and K. Hirahara, How decp can we see the high velocity anomalies beneath the Japan islands, Geophys. Res. Lett. 15, 828-831, 1988.

Nolet, G., Solving or resolving inadequate or noisy tomographic systems, J. Comp. Phys., 61, 463-482, 1985.

Nolet, G. (Ed), Seismic tomography, Reidel, Dordrecht, pp. 386, 1987.

Richter, F. M., Focal mechanisms and seismic energy release of deep and intermediate earthquakes in the Tonga-Kermadec region and their bearing on the depth extent of mantle flow, $J$. Geophys. Res., 84, 6783-6795, 1979.

Silver, P. G., and W. W. Chan, Observations of body wave multipathing from broadband seismograms: evidence for lower mantle slab penetration beneath the Sea of Okhotsk, $J$ Geophys. Res., 91, 13,787-13,802, 1986.

Silver, P., R. W. Carlson, and P. Olson, Deep slabs, geochemical heterogeneity, and the large-scale structure of mantle convection, Ann. Rev. Earth Planet. Sci., 16, 477-541, 1988.

Slecp, N. H., Telcseismic P-wave transmission through slabs, Bull. Seismol. Soc. Am., 63, 1349-1373, 1973.

Spakman, W., Upper mantle delay time tomography, Ph.D. thesis, University of Utrecht, pp. 200, 1988.

Spakman, W., and G. Nolet, Imaging algorithms, accuracy and resolution in delay time tomography, in Mathematical Geophysics, edited by N. J. Vlaar, G. Nolet, M. J. R. Wortel and S. A. P. L. Cloetingh, pp. 155-187, Reidel, Dordrecht, The Netherlands, 1988.

Spakman, W., M.J.R. Wortel, and N. J. Vlaar, The Hellenic subduction zone: a tomographic image and its geodynanic implications, Geophys. Res. Lett., 15, 60-63, 1988.

Thurber, C. H., and K. Aki, Three dimensional seismic imaging, Ann. Rev. Earth Planet. Sci., 15, 115-139, 1987.

Toksoz, M.N., J.W. Minear, and B.R. Julian, Temperature field and geophysical effects of a downgoing slab, J. Geophys Res., 76, 1113-1138, 1971.

Toksoz, M. N., N. H. Sleep, and A. T. Smith, Evolution of the downgoing lithosphere and mechanisms of deep focus earthquakes, Geophys. J. R. astron. Soc., 35, 285-310, 1973.

Van der Hilst, R.D., A 3-D image of large scale structures in the mantle below the caribbean region, Annales Geophysicae, EGS abstracts, 38, 1989

Van der Hilst, R.D. and W. Spakman, Importance of the reference model in linearized tomographic inversions: images of subduction below the Caribbean plate, Geophys. Res. Lett., in press, 1989

Vidale, J. E., Waveform effects of a high velocity subducted slab, Geophys. Res. Lett., 14, 542-545, 1987.

Wortel, M.J.R., Age-dependent subduction of oceanic lithosphere, Ph.D. Dissertation, University of Utrecht, Utrecht, The Netherlands, 1980.

Wortel, M.J.R, and N.J. Vlaar, Subduction zone seismicity and the thermo-mechanical evolution of downgoing lithosphere, Pageoph 128, 625-659, 1988.

Zhou, H., How well can we resolve the deep seismic slab with seismic tomography?, Geophys. Res. Lett. 15, 1425-1428, 1989.

W. Spakman, Rob van der Hilst and Rinus Wortel, Institute of Earth Sciences, University of Utrecht, P.O. Box 80.021, 3508 TA Utrecht, The Netherlands.

Scth Stein, Department of Gcological Sciences, Northwestern University, Evanston, IL 60208, USA.

(Received: July 3, 1989;

Accepted: August 5, 1989) 